\title{
REVIEW
}

\section{ROLE OF COLONOSCOPY IN COLORECTAL CANCER}

Sergio Eduardo Alonso Araujo, Paulo Roberto Arruda Alves and Angelita HabrGama

RHCFAP/3032

ARAUJO SEA et al. - Role of colonoscopy in colorectal cancer. Rev. Hosp. Clín. Fac. Med. S. Paulo 56(1):25-35, 2001.

Colorectal cancer (CRC) represents the third most common malignancy throughout the world. Little or no improvement in survival has been effectively achieved in the last 50 years. Extensive epidemiological and genetic data are able to identify more precisely definite risk-groups so screening and early diagnosis can be more frequently accomplished. CRC is best detected by colonoscopy, which allows sampling for histologic diagnosis. Colonoscopy is the gold standard for detection of small and premalignant lesions, although it is not cost-effective for screening average-risk population. Colonoscopic polypectomy and mucosal resection constitute curative treatment for selective cases of invasive CRC. Similarly, alternative trans-colonoscopic treatment can be offered for adequate palliation, thus avoiding surgery.

DESCRIPTORS: Colorectal cancer screening. Colorectal cancer diagnosis. Colonoscopy. Colorectal polyps. Flat lesions.

Colorectal cancer (CRC) represents the third most common malignancy worldwide ${ }^{1}$ and the second leading cause of cancer-related death in the U.S., regardless of sex. In 1998, it is estimated that 20000 cases were newly diagnosed, and 6000 Brazilians died of the disease ${ }^{2}$. Five-year associated mortality remains unchanged around $50 \%{ }^{3}$; advances in the operative technique and adjuvant therapy produced a modest impact on survival ${ }^{4}$.

In this paper, a brief review of aspects of etiology, epidemiology, genetics, histology, and main determinants of prognosis of CRC will be followed by an in-depth evaluation of the role of colonoscopy in the screening, diagnosis, treatment, and surveillance of patients with CRC.

\section{ETIOLOGY AND EPIDEMIOLOGY}

The colorectum is the most frequent site for primary cancers in the human body. Adenocarcinomas represent almost all CRCs. There are several etiologic determinants of CRC, since multiple steps are involved in its occurrence. Several genetic mutations have been detected, and exogenous factors interact for the development of the acquired ones.

Sporadic CRC, or CRC not associated with inheritance, occurs more commonly after the age of 60 and has

From the Department of Gastroenterology, Hospital das Clínicas, Faculty of Medicine, University of São Paulo. the sigmoid colon or rectum as the primary site in up to $65 \%$ of cases.

Known factors related to $\mathrm{CRC}$ etiology include:

- diet: High insoluble fiber intake seems to protect against $\mathrm{CRC}^{5}$. Saturated fat intake in an amount greater than $20 \%$ of meal calories result in elevated cancer risk. Some studies suggest that calcium has protecting effects ${ }^{6,7,8}$. Elevated refined sugar intake may predispose to adenomas ${ }^{9}$.

- smoking: An increase in carcinoma incidence after a tobacco exposure period greater than 35 years has been demonstrated ${ }^{10}$.

- radiotherapy: Pelvic irradiation is associated with an elevated risk of rectal cancer ${ }^{11,12}$. 
- inflammatory bowel disease: Patients with ulcerative pancolitis or ulcerative colitis (UC) diagnosed at a young age are more susceptible to $\mathrm{CRC}^{13}$. Cumulative incidence of low- and high-grade dysplasia can reach $90 \%$ and $25 \%$ respectively after 37 years. Biopsy findings of low-grade dysplasia are associated with a $10 \%$ cancer-risk; high-grade dysplasia between $30 \%$ and $40 \%$ and dysplasia associated-lesion or mass is associated with a risk greater than $50 \%$. Von Herbay et $\mathrm{al}^{14}$ found that invasive CRC is associated with high-grade dysplasia in $100 \%$ of cases. CRCs in UC are more usually infiltrative and exhibit mucinous histology. Sulfasalazine therapy seems to reduce the cancer risk associated with UC. In patients with Crohn's disease, cancer risk is hard to define. Nevertheless, longstanding disease and a narrowed lumen at colonoscopy may call endoscopists to attention.

- adenomas: Most CRCs arise from preexisting adenomatous polyps $^{15,16}$. Geographic and topographic distribution of adenocarcinomas is similar to adenomas. There is ethnic conformity. Onethird of resected cancer specimens include adenomas in a 6-times elevated prevalence when compared to control groups without cancer. Residual adenoma foci can be usually identified in adenocarcinomas, and the atypia degree of an adenoma is directly related to its $\operatorname{size}^{17}$. Nevertheless, the strongest indirect evidence for the adenomacarcinoma sequence comes from the National Polyp Study in the U.S. In this study, a 6-year followup of patients who underwent colonoscopic polypectomy, when all polyps found were excised, there was a $76 \%$ to $90 \%$ decrease in CRC incidence when compared to 3 control groups matched for age $^{18}$. Cancer risk of an adenoma is related to its size and to villous histology ${ }^{19,20}$.

- cancer de novo: There is little doubt that CRC can arise from colorectal mucosa without a pre-existing adenomatous lesion ${ }^{21}$, although the clinical significance of this assumption remains unknown. Findings of early CRC, especially in flat-depressed lesions, have been described by several endoscopists, especially in Japan ${ }^{22,23,24,25}$. Flat adenomas ${ }^{26}$ appear as reddish plaquelike areas that are raised slightly above the surrounding mucosa, with or without a central depression that exhibit air induced deformation (the shape of the lesion changes after gas aspiration during colonoscopy). Histologically, they are tubular adenomas where the height of the adenomatous component does not exceed twice the height of the surrounding normal mucosa. A high incidence of atypia has been consistently reported for flat adenomas $^{26}$, and there is a general assumption not only in $\operatorname{Japan}^{27,28,29,30}$ that CRC can rapidly arise from these diminutive lesions, which can be missed in conventional colonoscopy.

\section{GENETIC FINDINGS AND HEREDITARY CRC}

$\mathrm{CRC}$ is a genetic disease. Accumulation of hereditary or acquired genetic changes results in the development of adenocarcinoma cells in colorectal mucosa that have a growth advantage since they do not respond to the normal determinants of cell growth, differentiation, and death, leading to dysplasia and invasive cancer ${ }^{31,32}$. Oncogenes (K-ras), tumor-suppressor genes (APC, DCC e p53), and DNA (deoxyribonucleic acid) mismatch repair genes (MSH2, MLH1, PMS1, PMS2 e
MSH6) represent the three classes of altered genes involved in CRC carcinogenesis.

It is estimated that in up to $15 \%$ of cases, CRC results from an initial hereditary genetic defect. In these cases, $\mathrm{CRC}$ is part of a syndrome and is called hereditary non-polyposis colorectal cancer (HNPCC). HNPCC patients are unable to repair DNA replication errors, since a MMR gene mutation is detected in these cases. In these patients, CRC develops more rapidly (usually before age 50) in the proximal colon. It is preceded by a few or no polyps, is more frequently multiple, and can be associated with other cancers, such as breast, endometrial, ovarial, pancreas, stomach, and kidney $^{33}$.

In $1 \%$ of all cases, CRC is associated with hundreds or thousands of large bowel adenomas, as well as periampullar adenomas or carcinomas and desmoid tumors, as a result of a dominant hereditary pattern or genetic mutation. This phenotype is known as familial adenomatous polyposis (FAP). FAP results from mutation or deletion of the tumor suppresser gene APC (adenomatous polyposis coli). In up to $20 \%$ of FAP cases, the genetic defect is not inherited. In these patients, CRC arises from neoplastic changes in one or more of the colorectal adenomas in virtually all cases up to 45 years of age if the entire large bowel is not surgically removed.

\section{HISTOLOGIC AND MACROSCOPIC FINDINGS}

Carcinoma in situ refers to the presence of malignant cells exclusively above the muscularis mucosa layer. It is also known as superficial carcinoma or severe dysplasia. Intraepithelial carcinoma refers to malignant cells exclusively inside the epithelium. They are restricted to the crypts of Lieberkühn. 
Invasive colorectal cancer (malignant cells invading through the muscularis mucosa layer to the submucosal layer) is observed in up to $9 \%$ of colorectal polyps removed in colonoscopy $^{34,35}$.

More commonly, early CRC presents in three forms: (1) malignant adenoma or polypoid carcinoma; (2) a malignant focus in a sessile adenoma; or (3) a small ulcerated cancer. However, according to several Japanese endoscopists early CRC are more frequently flat depressed diminutive lesions $^{36-42}$.

The classification of Haggitt ${ }^{44}$ for early CRC is familiar to most gastroenterologists, endoscopists, and colorectal surgeons. A polyp is pedunculated when the length of the pedicle is larger than its diameter ${ }^{45}$. In Haggitt's classification, we define 4 levels of invasion for pedunculated polyps:

- Level 0 - carcinoma above the level of muscularis mucosa (in situ);

- Level 1 - submucosal invasion limited to the head of the polyp;

- Level 2 - carcinoma invading the level of the neck of the adenoma;

- Level 3 - carcinoma invading any part of the stalk; and

- Level 4 - invasion of the submucosal layer of the bowel wall at the base of the polyp.

According to Haggitt's classification, all sessile polyps with invasive CRC represent level-4 invasion. However, authors from Japan classified sessile lesions into 3 levels ${ }^{46,47}$ :

- $\mathrm{sm}_{1}$ - slight submucosal invasion;

- $\mathrm{sm}_{2}$ - intermediate between $\mathrm{sm}_{1}$ and $\mathrm{sm}_{3}$; and

- $\mathrm{sm}_{3}$ - invasion into the full thickness of the submucosa and internal surface of the muscularis propria.

For pedunculated polyps, Haggit's level 1 is comparable to $\mathrm{sm}_{1}$, levels 2 and 3 are comparable to $\mathrm{sm}_{2}$, except when the invasion is deep down in the contact with the muscularis propria, in which case it becomes $\mathrm{sm}_{3}$.

When looking for atypia in diminutive colorectal lesions, no large US study has reproduced the high-grade dysplasia or severe atypia rate reported by the Japanese. The US National Polyp Study in 1984 (seven centers) examined 572 diminutive adenomas and showed only $0.9 \%$ high-grade dysplasia $^{48}$. Muto reports up to $13 \%{ }^{26}$ and Mitooka, $13.5 \%{ }^{49}$. It seems that there is a growing consensus about the need for applying chromoscopy and magnification in Western populations in a prospective surveillance for flat lesions that can be missed during conventional colonoscopy.

Macroscopic appearance of early CRC was established according to the classification for early gastric cancer of the Japanese Society for Gastrointestinal Endoscopy ${ }^{50}$. Diminutive lesions can be divided in three classes: elevated, flat, or depressed. Each of these has some subdivisions to describe a pedicle or a central depression. It seems that since these microscopic features may vary according to intensity of light, air deformation, and amount of contrast, there may be a significant variability between endoscopists when trying to classify these lesions.

When describing large or advanced CRC, endoscopists may use Borrmann's morphologic classification for advanced gastric cancer ${ }^{51}$. Accordingly, CRC can present in four distinctive forms: polypoid, ulcerated-vegetant, ulcerated-infiltrative, and diffuse-infiltrative.

The usual microscopic colorectal adenocarcinoma pattern is tubular with or without papillary areas, well or moderately differentiated (50\% to $87 \%$ of CRCs ${ }^{52}$ ). In up to $20 \%$ of cases, the glandular shape is irregular or there is no shape (poorly differentiated cancers). Most CRCs have well defined expansive margins (not infiltrative). Mucinous tumors may be observed in up to $15 \%$ of cases, and they are de- fined by the presence of mucin in a volume of at least $50 \%$ of the whole lesion. The mucin may be within the cell (signet ring cells) or without. Mucinous tumors are associated with young males, villous adenoma, radiotherapy, and inflammatory bowel disease $^{53}$.

\section{SCREENING}

Screening is the search for cancer and precancerous polyps (adenomas) in asymptomatic persons. Physicians and lay persons are becoming increasingly aware that most CRCs and most deaths are preventable through screening.

Colonoscopy with polypectomy represents only one method to find and remove premalignant lesions in the entire large bowel. Although colonoscopy follows and exceeds the principles of screening (since polyps are removed), there is no study in a randomized or case control setting to demonstrate its effectiveness in reducing mortality associated with CRC. Available evidence that favor colonoscopy are: case control studies demonstrated a $60 \%-70 \%$ reduction in CRC mortality in the distal colon from sigmoidoscopy and polypectomy; a cohort of patients who underwent colonoscopy and clearing of adenomas experienced a 76\%-90\% reduction in CRC incidence compared to reference populations; cross-sectional studies of screening colonoscopy in average-risk population demonstrate a prevalence of adenomas more than twice that detected on average by flexible sigmoidoscopy; currently, near $40 \%$ of all CRCs in the US arise proximal to the splenic flexure ${ }^{54}$.

In spite of these advantages, the need for bowel preparation, sedation, and risks associated with the exam itself or polypectomy constitute the main causes for the low population adherence to screening programs including colonoscopy. Nevertheless colonos- 
copy may be used as the preferred screening strategy for the average-risk population (persons age 50 and older who have no risk factors for CRC other than age). In this population, full colonoscopic examination may be done every 10 years as an alternative to flexible sigmoidoscopy every 5 years plus annual fecal occult blood testing ${ }^{54}$.

Colonoscopy remains the choice screening method for those with high and moderately increased risk for CRC ${ }^{55}$. It is estimated that these individuals account for $20 \%$ to $30 \%$ of population $^{56}$ :

- individuals with a family history of CRC in a single first-degree relative at age $>55$ year. Start colonoscopy at age 50 and repeat at 5- or 10-year intervals;

- individuals with a family history of CRC in a single first-degree relative at age $<55$ year or in two or more first-degree relatives at any age. Start colonoscopy at age 40 or 10 years before the youngest age that cancer was diagnosed. Repeat at 5 year intervals;

- personal history of $1 \mathrm{~cm}$ - or larger polyp or multiple polyps of any size. Repeat colonoscopy 1 year after polypectomy and at 5 year-intervals between negative exams;

- personal history of CRC - see CRC surveillance.

\section{ENDOSCOPIC DIAGNOSIS AND STAGING}

In contrast to CRC screening, there is a need for diagnosis when symptoms are observed. In the majority of these cases, the endoscopist can expect findings of advanced colorectal cancer.

When efficacy of endoscopy and barium enema in the diagnosis of CRC are compared with colonoscopy, a significant bias can be expected due to the expertise and medical specialty of the authors. However, it seems reasonable to conclude that colonoscopy would be the most effective exam for the large bowel and terminal ileum, since it permits direct identification of the tumor, histologic examination through biopsy, diagnosis and removal of synchronic polyps, and staging attempts through endoscopic ultrasound (EUS) techniques. Sporadic CRC is associated with synchronous cancer in up to $4 \%^{57}$ and to synchronous adenomas in up to $25 \%{ }^{58}$ of cases. Supplemental colonoscopy may follow barium enema in up to $40 \%$ of cases due to inadequate preparation or reasonable doubt $t^{59}$. Barium enema sensitivity for the diagnosis of CRC in patients with positive fecal occult blood testing remains between $50 \%$ and $75 \%{ }^{60}$. Nevertheless, for double contrast barium enema, there can be similarity between radiologic and endoscopic methods for the diagnosis of CRC in asymptomatic individuals ${ }^{60}$. Although this may be true, additional information regarding histology, search for synchronous polyps, and flat lesions through chromoscopy and staging will be lacking with barium enema alone.

Colonoscopy has limitations in the diagnosis of CRC. A lower sensitivity should be expected in conditions of poor bowel preparation as seen in diverticular disease, for some locations in the large bowel known as "blind" regions (behind large bowel folds and in segments where intubation was technically demanding) and in cases when complete examination couldn't be attempted.

Carcinoma in situ is more commonly a histologic diagnosis of a polypoid lesion excised during colonoscopy. Reports of lymph node metastasis for in situ or intramucosal carcinomas are anecdotal ${ }^{61}$. Therefore, for lesions with clear histologic margins, complete resection by endoscopy remains a sufficient curative treatment ${ }^{44,62,63}$.
Symptomatic individuals usually present with advanced lesions. Endoscopic findings may easily follow Borrmann's nomenclature. Advanced lesions are usually greater than $2 \mathrm{~cm}$, indurated, present with irregular surface and spontaneous ulcerations, and usually bleed after biopsy. There is little mobility following manipulation with the snare, and for those lesions eventually considered for total excision through endoscopic mucosal resection, little or no elevation may be observed after submucosal injection of saline. Advanced CRC represents a lesion with detected invasion into the muscularis propria. Oncologic colon resection is recommended treatment for colon lesions. For advanced rectal lesions, surgical treatment is indicated. This approach encompasses local resection, anterior resection, or abdominoperineal resection. For advanced rectal lesions, pre- or postoperative adjuvant treatment is recommended for cure.

The presence of early CRC remains the challenge for diagnostic colonoscopy. Since endoscopic resection may be sufficient treatment in some situations, there is a need for precise endoscopic diagnosis of the level of invasion. EUS, chromoscopy, and magnifying colonoscopy (MC) are useful tools in the diagnosis of CRC as well as for immediate staging.

\section{Chromoscopy}

Using a conventional endoscope, the surface of the colon appears smooth. But when looking more closely, the mucosa would actually appear granular and be divided by innominate grooves into "colon areas". The granular appearance of these colon areas is due to numerous pits in the colonic mucosa, which represent the crypts of Lieberkühn (intestinal glands). These minute pits are arranged regularly and are round in shape. The diameter of each pit is 40 to $50 \mu \mathrm{m}$. Two methods 
— chromoscopy and MC - are currently used to see the colon surface more clearly and are being used together or separately.

Tissue staining can be accomplished during colonoscopy by injection, spraying with a catheter, ingestion of a capsule, or enema ${ }^{64}$. Tissue stains may be divided into three categories. The first uses absorptive stains that identify specific cells or cell components. Methylene blue may identify colorectal neoplastic lesions since absence of staining usually indicates neoplastic change. Another absorptive stain is cresyl violet, which stains the margins of the pits on the mucosal surface allowing a very clear definition of the pit pattern. The second category is reactive stains that identify cellular products through color change as a result of a $\mathrm{pH}$ shift. Congo red changes from red to dark blue when $\mathrm{pH}<3$ and can be used to enhance visualization of diminutive colorectal lesions ${ }^{65}$. The third category is contrast stains. Not absorbed by the epithelium, they highlight tissue topography by pooling in epithelial crevices and depressions. Indigo carmine $0.4 \%$ to $4 \%$ is the best example in this category.

Since chromoscopy highlights perception of the epithelial surface, there may be potential to enhance endoscopic diagnosis of diminutive colorectal lesions when stains are used in an orderly fashion. Nevertheless, it has not yet been possible to reliably predict the histologic diagnosis using chromoscopy and conventional endoscopy. George et al. ${ }^{64}$, using contrast chromoscopy with $0.2 \%$ indigo carmine dye and conventional colonoscopy could correctly predict histologic diagnosis in only $47 \%$ of 89 diminutive colorectal lesions $(<5 \mathrm{~mm})$. Polypectomy may routinely follow diagnosis of all lesions through chromoscopy.

\section{Magnifying colonoscopy (MC)}

MC consists in the utilization of an optical system assembled to a video- colonoscope. This endoscope has the ability to produce a magnified view (3X to $170 \mathrm{X}$ ) of the entire colorectal mucosal surface. Magnification can be automatic or may follow manual activation.

The ability to predict the histology of polyps on endoscopic examination remains a fascinating challenge that could reduce CRC screening and surveillance costs. The final goal of MC is in vivo histologic diagnosis through magnified observation of pit patterns in identified lesions. During MC, the ordinary detection of a lesion is followed by mucus washout with water jet and contrast or absorptive chromoscopy. Magnified observation permits pit pattern analysis in the lesion and subsequent classification. After stereomicroscopic observation of 1676 lesions, Kudo ${ }^{66}$ proposed 5 categories in his pit pattern classification. According to his experience, neoplastic lesions were adequately differentiated from non-neoplastic ones. Kudo states that correct pit pattern evaluation only can be done at $100 \mathrm{X}$ magnification at which adequate focus is hard to obtain, so the procedure becomes technically difficult. Another interesting property of MC is the ability to define the degree of invasion of a colorectal lesion. According to Kudo, the fifth category of his classification (V) would indicate massive invasion of the submucosal layer. It seems reasonable to admit that pit pattern analysis correlates to the histologic diagnosis. However, we understand that the sensitivity of the qualitative diagnosis, as well as the accuracy of diagnosis by MC of submucosal invasion, remains to be determined.

\section{Virtual colonoscopy (VC)}

Computed tomography (CT) colography, or VC, generates high resolution two- and three-dimensional images of the entire colorectal structure. It represents an attractive alterna- tive for diagnosis and screening for CRC. VC involves data input from a helical CT scanner, which is then processed by advanced computer software. The main related advantages are: 1. VC foregoes colon intubation and results in no risk of colon perforation; 2. there is no need for sedation and better acceptance may be accomplished; 3. full colon evaluation can be expected even for patients where conventional colonoscopy cannot be attempted; 4. VC provides the exact location of diagnosed lesions. However VC still demands full bowel preparation in order to enhance sensitivity and specificity, since fecal residues may be interpreted as elevated lesions. Experimental evidence shows that irradiation is less than half of the amount used during barium enema. Initial reports state that sensitivity and specificity are $100 \%$ for polyps > $1 \mathrm{~cm}$; for polyps > $0.5 \mathrm{~cm}$, sensitivity was $100 \%$ and specificity was $80 \%$, and for polyps $<0.5 \mathrm{~cm}$, sensitivity was $42 \%$. Several technical problems and diagnostic issues must be addressed before $\mathrm{VC}$ is incorporated into practice: 1 . enhancing image resolution to detect diminutive and flat lesions; 2 . refining image subtraction technology to minimize misdiagnosis due to fecal residues; 3 . evaluating collapsed colon segments even after pneumocolon; and 4. reducing costs mainly related to image analysis ${ }^{67}$.

\section{Endorectal (ERUS) and endoscopic ultrasound (EUS)}

Introduced by Dukes in $1928^{68}$ for rectal adenocarcinoma, pathologic staging still remains the strongest predictor of survival for patients with $\mathrm{CRC}^{53,69}$. CRC staging refers to the exact knowledge of the degree of tumor infiltration in the bowel wall, the extent and location of lymph node involvement and the presence of distant metastasis. 
CRC does not lead to lymph node metastasis if malignant cells are above the muscularis mucosa ${ }^{70}$. For early CRCs, lymphatic spread can be expected in $4 \%$ of cases ${ }^{71}$ if the cancer is well or moderately differentiated. For CRCs invading through the muscularis propria, lymph node metastasis are expected in up to $20 \%$. When CRC reaches pericolic or perirectal tissues (complete invasion of the bowel wall), lymph nodes metastasis are observed in up to $58 \% \%^{72}$ of cases.

Rectal cancer staging can be accomplished with ERUS, since the tumor is accessible by the probe. ERUS may follow a distal washout enema and foregoes sedation and x-rays. Accuracy for diagnosis of depth of penetration in the rectal wall reaches $93 \%^{73}$ and for lymph node involvement is $84 \%{ }^{74}$. It has been demonstrated that preoperative chemoradiation therapy induces significant and sometimes complete tumor regression. Therefore, postchemoradiation staging is necessary in order to evaluate tumor response and further treatment. However, the accuracy of ERUS for the diagnosis of penetration depth after chemoradiation as first line treatment for low rectal cancer is only $8.3 \%{ }^{75}$.

The development of high-frequency and small-size EUS probes has stimulated endoscopists to use this imaging modality to produce a significant improvement in the correct diagnosis of suspected submucosal lesions or extrinsic masses, as well as, most importantly, in ruling out invasive submucosal layer invasion or advanced cancers, since both findings preclude any attempt of endoscopic therapy of suspected benign or early malignant colorectal lesions. The accuracy of EUS for the diagnosis of invasive cancer is around $76 \%$. For intramucosal carcinomas, accuracy was $83 \%$, for early invasive cancers, $90 \%$, but for advanced cancer, 50\% $\%^{76}$. Overall accuracy for the diagnosis of bowel wall depth of invasion using EUS is between $70 \%$ and $90 \%{ }^{77,78}$.

\section{ENDOSCOPIC TREATMENT OF CRC}

\section{The malignant polyp}

Complete endoscopic excision with clear histiologic margins is sufficient treatment for in situ and intramucosal carcinomas. Incomplete resection leads to invasive cancer. Contrast chromoscopy enhances definition of resection margins.

When considering curative endoscopic treatment of early CRC, it is critical to recognize that oncologic colectomy is the only method for demonstrating and harvesting lymph node involvement. When dealing with cancer, cure and survival remain central objectives. Therefore, any attempts at endoscopic treatment on a day-by-day basis should be done considering results of surgical options available after a multi-specialty (pathologist, endoscopist, and surgeon) consensus.

For pedunculated polyps with invasive cancer, the presence of malignant cells invading the submucosa at the polyp's head (Haggitt's level 1), neck (level 2), or stalk (level 3) results in overall low risk of lymph node involvement ${ }^{44,63,79,80-82}$. Cranley ${ }^{83}$ showed in a review of 17 experiences, including 589 pedunculated malignant polyps (polyps with invasive cancer), that only $1 \%$ of the polyps with "good" histology (good/moderate differentiation, 2 mm-clear margin at the stalk, and no vascular invasion) resulted in cancer diagnosis at laparotomy or led to recurrence. Nevertheless, pedunculated polyps with invasive cancer at Haggit's level 4, as well as sessile polyps with invasive cancer at the submucosal layer, may exhibit lymph node involvement in up to $10 \%{ }^{71,84}$ of cases. According to Muto ${ }^{85}$, the risk of lymph node involvement for early invasive sessile cancers of the $\mathrm{sm}_{3}$ level of submucosal invasion is between $27 \%$ and $69 \%$. For pedunculated polyps with neoplastic involvement observed at the stalk, an adverse outcome may be observed in up to $13 \%{ }^{86}$ of cases. Almost all of these patients had poorly differentiated cancers with lymphatic or blood vessel invasion.

The precise definition of clear margins ( 2 to $3 \mathrm{~mm}$ between lesion margins and diathermy margins according to Muto ${ }^{85}$ ) is a problem that remains to be solved, and incomplete resection is a well known cause for recurrence or invasive cancer. Some authors believe that a portion of the therapeutic failures associated with sessile lesions come from incomplete resections due to underestimating the position of the margin of the lesion. Endoscopic tattooing is unequivocally a wise routine decision in the management of larger sessile lesions, since it allows histologic processing and definitive diagnosis followed by a guided endoscopic, laparoscopic, or either open salvage procedure if necessary ${ }^{87,88}$.

When dealing with advanced CRC, a representative tumor fragment must be taken from central area of the lesion since marginal specimens may be frequently re-epithelized or exhibit pure adenomatous component.

For pedunculated lesions, snare diathermy polypectomy remains adequate treatment. For large stalks, use of heater probe or 1:10 000 epinephrine injection may optimize resection through avoidance of bleeding. For sessile lesions $2.5 \mathrm{~cm}$-size or less, endoscopic mucosal resection assisted with saline submucosal injection is recommended. For larger lesions, piecemeal or sequential resections are the best alternatives.

Endoscopic findings that may anticipate elevated risk of bowel perforation or raise the possibility of dealing with an advanced cancer are: lesions 
larger than $40 \mathrm{~mm}$; central depression observed after chromoscopy, non-lifting signal after submucosal saline injection; diagnosis of pit patterns III and $\mathrm{V}$ at MC, and, obviously, EUS diagnosis of massive invasion of the submucosa.

Equal or greater care must be taken when dealing with specimen conservation. Immediately before formalization, sessile lesions must be fixed with pins, pedunculated lesions must be longitudinally sectioned, and the stalk must be clearly identified with a pin.

\section{Endoscopic palliative treatment for obstructive CRC}

Intestinal obstruction is a frequent clinical presentation of left-sided tumors. Radical treatment through an oncological operation is the treatment of choice when cure is attempted, and palliative resections may de done through laparoscopy or conventional access with the aim of symptomatic relief and prevention of obstruction. When cure cannot be achieved, avoiding a colostomy may optimize quality of life. Colonoscopy may have a role in these situations.

Laser (Nd:YAG) ablation was proven to be safe and effective for avoiding intestinal obstruction from advanced colorectal lesions. In a 7-center, 60-patient European experience ${ }^{89}$, an $80 \%$ rate of response was observed, and mortality associated with laser therapy was $3.3 \%$. Schulze and Lyng ${ }^{90}$ evaluated the Nd:YAG laser for endoscopic tumor ablation in 74 disseminated CRC patients. Symptomatic relief was observed in $74 \%$. There was no mortality; however, the authors detected 5 cases of perforation and 1 of bleeding. The main advantages of laser ablation include the possibility of multiple sessions and no need for anaesthesia. Perforation is the primary concern, and stenosis may occur lead- ing to urgent colostomy. Laser ablation may be used in the preoperative setting for patients with partial or complete intestinal obstruction ${ }^{91,92}$. Laser ablation may reduce tumor size and alleviate obstruction so careful bowel prep can be delivered. Laser-associated costs remain uniformly elevated, and financial burden remains main reason for its limited availability in most centers.

Photodynamic therapy (PDT) is a treatment modality in which limited cell death and tissue necrosis result from interaction between a photosensitizing agent taken up by a neoplastic tissue and a defined wave-length lowpower light ${ }^{93}$. There is no thermal effect, so perforation risk is decreased. Target tissue cells exposed to the agent (more commonly, a hematoporphyrin derivative administered intravenously) undergo selective death in the presence of oxygen. The mucosal layer is more affected as result of agent-affinity and light penetration. Associated cutaneous photosensitivity may be severe, persists for up to 6 weeks, and represents the main drawback, since severe burns may occur from solar exposure.

Insertion of expandable metal stents for non-surgical palliation in patients with symptomatic near-obstructive colonic tumors may be achieved through a single endoscopic examination, as opposed to laser therapy in which multiple sessions are required, and thus representing an attractive alternative. Rey et al. ${ }^{94}$ described their experience with 12 patients with rectosigmoid carcinoma. In this series, there were no complications associated with the prosthesis, although migration occurred in 3 patients, necessitating stent removal. Saida et al..$^{95}$ published results of a 15-patient series in which stent insertion was undertaken prior to bowel prep and elective resection for obstructive CRC. There were 2 perforations and 1 migration. In the remain- ing 13 patients, bowel prep was considered adequate during the operation. Perforation, migration, pain, and tumor overgrowth represent the main obstacles for stent treatment, and results of flexible metallic mesh prosthesis insertion need further evaluation ${ }^{96}$.

\section{SURVEILLANCE}

Patients who undergo endoscopic mucosal resection of an invasive carcinoma may need endoscopic re-examination up to 6 months after resection, although there is no available evidence of benefit from this approach.

For patients with non-early CRC who underwent radical surgery, there is reasonable doubt about the role of surveillance colonoscopy in the diagnosis of potentially curative recurrences, since most of them occur as an extrinsic growth. For 113 cases of recurrence reviewed by Virgo et al..$^{97}$, colonoscopy could first demonstrate recurrence in only 3 cases.

Although definitive evidence is still lacking, there may be some survival benefit associated with dedicated follow-up, since colonoscopy combined with clinical, laboratory, and image evaluations, and more recently with the aid of positron emission tomography, remain the only way to diagnose resectable recurrences.

Major attention should be paid to the need of at least one full colonoscopic evaluation when the first diagnosis of CRC is done. For obstructing lesions, postoperative examination may follow an interval not greater than 6 months. Virtual colonoscopy may have a role in this setting. According to the American Cancer Society, American College of Gastroenterology, and American Society of Colon and Rectal Surgeons, further examinations are recommended on a 3- to 5-year basis ${ }^{55}$. 
ARAUJO SEA et al. - Papel da colonoscopia no câncer colorretal. Rev. Hosp. Clín. Fac. Med. S. Paulo 56(1):25-35, 2001.

O câncer colorretal (CCR) é a terceira neoplasia maligna mais freqüente no mundo. No entanto, pouco ou nenhum benefício de sobrevida foi obtido nos últimos 50 anos. Quanto à doença genética, crescente investigação epidemiológica e de genética molecular apontam para a definição de gru- pos de risco, específicos para o CCR, favorecendo a aplicação de protocolos de rastreamento e possibilitando maior diagnóstico precoce. O CCR é melhor diagnosticado pelo exame colonoscópico que possibilita diagnóstico histológico através da biópsia. Lesões pré-malignas e cânceres precoces são diagnosticados preferencialmente pela colonoscopia em nosso meio. No entanto, significativa redução de custos se faz necessária à sua aplicação no rastreamento da população de risco normal para CCR. A polipectomia e a mucossectomia endoscópicas representam tratamento curativo para casos selecionados de CCR invasivo. Da mesma forma, adequada paliação pode ser alcançada utilizando alguns recursos da colonoscopia.

DESCRITORES: Rastreamento do câncer colorretal. Diagnóstico do câncer colorretal. Colonoscopia. Pólipos colorretais. Lesões.

\section{REFERENCES}

1. SHIKE W, WINAWER SJ, GREENWALD PH et al. - Primary prevention of colorectal cancer: the WHO Collaborating Centre for the Prevention of Colorectal Cancer. Bull World Health Organ 1990; 68: 377-85.

2. BRASIL. MINISTÉRIO DA SAÚDE - INSTITUTO NACIONAL DO CÂNCER / PRO-ONCO - Estimativa da Incidência e Mortalidade por Câncer no Brasil, Rio de Janeiro, 1998.

3. BORING CC, SQUIRES TS \& TONG T - Cancer Statistics 1993. CA Cancer J Clin 1993; 43:7-27.

4. KROOK JE, MOERTEL CG, GUNDERSON LL et al. - Effective surgical adjuvant therapy for high-risk rectal carcinoma. N Engl J Med 1991; 324: 709-15.

5. NURKITT DP - Epidemiology of cancer of the colon and rectum. Cancer 1971: 28: 3-13.

6. FAIVRE J, WILPART M \& BOUTRON MC - Primary prevention of large bowel cancer. Recent Results Cancer Res 1992; 122: 85-99.

7. NEGRI E, LA VECCHIA C \& D'AVANZO B - Calcium, dairy products and colorectal cancer. Nutr Cancer 1990; 13: 255-62.

8. STEMMERMANN GN, NOMURA A \& CHYOU PH - The influence of dairy and non-dairy calcium on subsite large bowel cancer risk. Dis Colon Rectum 1990; 22: 190-4.

9. MACQUART-MOULIN G, RIBOLI E, CORNÉE J et al. - Colorectal polyps and diet: a case-control study in Marseilles. Int $\mathbf{J}$ Cancer 1987, 40: 179-81.
10. GIOVANNUCCI E, RIMM EB, STAMPFER MJ et al. - A prospective study of cigarette smoking and risk of colorectal adenoma and colorectal cancer in US men. J Natl Cancer Inst 1994; 86:183-91.

11. LEVITT MD, MILLAR DM \& STEWART JO - Rectal cancer after pelvic irradiation. J R Soc Med 1990; 83: 152-4.

12. ROTMENSCH S, AVIGAD I, SOFFER EE et al. - Carcinoma of the large bowel after a single massive dose of radiation in healthy teenagers. Cancer 1986; 57: 728-31 .

13. MELLENKJAER L, OLSEN J, FRISCH $M$ et al. - Cancer in patients with ulcerative colitis. Int J Cancer 1995; 60: 330-3.

14. VON HERBAY A, HERFATH C \& OTTO HF - Cancer and dysplasia in ulcerative colitis: a histologic study of 301 surgical specimen. $\mathbf{Z}$ Gastroenterolol 1994; 32:382-8 [Germany].

15. MUTO M, BUSSEY JH \& MORSON BC - The evolution of cancer of the colon and rectum. Cancer 1975; 36:2251-70.

16. HILL M, MORSON BC \& BUSSEY HJ - Aetiology of adenomacarcinoma sequence in the large bowel. Lancet 1970; 1:245-7.

17. SHPITZ B, MEDL;INE A \& STERN H - The adenoma-carcinomasequence. In: MAZIER WP, LEVIEN DH, LUCHTEFELD MA et al. eds - Surgery of the Colon, Rectum, and Anus. Philadelphia, Saunders,1995. p.552-65.

18. WINAWER SJ, ZAUBER AG, HO MN et al. - Prevention of colorectal cancer by colonoscopic polypectomy. N Engl J Med 1993; 329: 1977-81. 
19. GATTESCHI B, COSTANTINI M, BRUZZI P et al. - Univariate and multivariate analysis of the relationship between adenocarcinoma and solitary and multiple adenomas in colorectal adenoma patients. Int J Cancer 1991; 49:509-12.

20. O'BRIEN MJ, WINAWER SJ, ZAUBER AG et al. - The National Polyp Study Workgroup. The national polyp study: patient and polyp characteristics associated with high-grade dysplasia in colorectal adenomas. Gastroenterology 1990; 98:371-9.

21. JASS JR - Do all colorectal carcinomas arise in preexisting adenomas? World J Surg 1989; 13:45-51.

22. KARIYA A - A case of early colonic cancer type IIc associated with familial polyposis coli. I to Cho (Stomach and Intestine) 1977; 12:1359. Apud: KUDO S - Early colorectal cancer: detection of depressed types of colorectal carcinoma. Tóquio, Igaku-Shoin, 1996.

23. KUDO S - Superficial depressed type (IIc) of colorectal carcinoma. Gastroenterol Endosc 1986; 28: 2811

24. IISHI H, NAKAIZUMI A, TATSUTA M et al. - Clinicopathologic features and endoscopic diagnosis of superficial early adenocarcinomas of the large intestine. Dis Dis Sci 1993; 38:1333-7.

25. MATSUMOTO T, IIDA M, YAO T et al. - Role of nonpolypoid neoplastic lesions in the pathogenesis of colorectal cancer. Dis Colon Rectum 1994; 37:450-5.

26. MUTO T, KAMIYA J, SAWADA T et al. - Small "flat adenoma" of the colon with special reference to its clinicopathological features. Dis Colon Rectum 1985; 28:847-51.

27. WOLBER RA \& OWEN DA - Flat adenomas of the colon. Hum Pathol 1991; 21: 70-4.

28. JARAMILLOE, WATANABEM, SLEZAK P et al. - Flat neoplastic lesions of the colon and rectum detected by high-resolution video-endoscopy and chromoscopy. Gastrointest Endosc 1995; 42:114-22.

29. FUJII T, REMBACKEN BJ, DIXON MF et al. - Flat adenomas in the United Kingdom - are treatable cancers being missed? Endoscopy 1999; 30: 437-43.

30. HART AR, KUDO S, MACKAY EH et al. - Flat adenomas exist in asymptomatic people: important implications for the colorectal cancer screening programmes. Gut 1998; 43:229-31.

31. VOGELSTEIN B, FEARON ER, HAMILTON SR et al. - Genetic alterations during colorectal tumor development. N Engl J Med 1988; 319: 525-32.

32. FEARON ER \& VOGELSTEIN B - A genetic model for colorectal tumorigenesis. Cell 1990; 61:759-67.

33. LYNCH HT, SMYRK TC, WATSON P et al. - Genetics, natural history, tumor spectrum and pathology of hereditary nonpolyposis colorectal cancer. Gastroenterology 1993; 104: 1535-49.

34. NUSKO G, MANSMANN U, PARTZSCH U et al. - Invasive carcinoma in colorectal adenomas: multivariate analysis of patient and adenoma characteristics. Endoscopy 1997; 29:626-31.

35. COOPER HS, DEPPISCH LM, GOURLEY WK et al. - Endoscopically removed malignant colorectal polyps: clinicopathological correlations. Gastroenterology 1995; 108: 1657-65.
36. CRAWFORD BE \& STROMEYER FW - Small nonpolypoid carcinomas of the large intestine. Cancer 1983; 51:1760-3.

37. ADACHI M, MUTO T, MORIOKA Y et al. - Flat adenomas and flat mucosal carcinomas (IIb type): a new precursor of colorectal carcinoma? Dis Colon Rectum 1988; 31:236-43.

38. DRIMAN DK \& RIDDELL RH - Flat adenomas and flat carcinomas: do you see what I see? Gastrointest Endosc 1994; 40:106-8.

39. HUNT DR \& CHERIAN M - Endoscopic diagnosis of small flat carcinoma of the colon: report of three cases. Dis Colon Rectum 1990; 33: 143-7.

40. KANAMORI T, ITOH M, YOKOYAMA Y et al. - Endoscopic and clinicopathologic evaluation of four cases of minute flat invasive colorectal carcinoma. Gastrointest Endosc 1996; 44:75-9.

41. KASUMI A, KRATZER GL \& TAKEDA M - Observations of aggressive, small, flat and depressed colon cancer. Surg Endosc 1995; 9:690-4

42. KURAMOTO S \& OOHARA T - Flat early cancers of the large intestine. Cancer 1989; 64:950-5.

43. MION F, DESSEIGNE F, NAPOLEON B et al. - Failure of endoscopic detection of a de novo carcinoma of the colon in a patient with adenomatous polyps. Gastrointest Endosc 1992; 38:703-6.

44. HAGGITT RC, GLOTZBACH RE, SOFFER EE et al. - Prognostic factors in colorectal carcinomas arising in adenomas: implications for lesions removed by endoscopic polypectomy. Gastroenterology $1985 ; 89: 328-36$.

45. WILCOX GM \& BECK JR - Early invasive cancer in adenomatous colonic polyps ("malignant polyps"): evaluation of the therapeutic options by decision analysis. Gastroenterology 1987; 92 (Pt 1): $1159-68$.

46. KUDO S - Endoscopic mucosal resection of flat and depressed types of early colorectal cancer. Endoscopy 1993; 25: 455-61.

47. KIKUCHI R, TAKANO M, TAKAGI K et al. - Management of early invasive colorectal cancer. Dis Colon Rectum 1995; 38: 1286-95.

48. GOTTLIEB LS, WINAWER SJ \& STERNBERG SS - National Polyp Study (NPS). The diminutive colon polyp. Gastrointest Endosc 1984; $28: 143$.

49. MITOOKA H, FUJIMORI T, OHNO S et al. - Chromoscopy of the colon using indigo carmine dye with electrolyte lavage solution. Gastrointest Endosc 1992; 38: 373-4.

50. KURTZ RC - Classification of early gastric cancer (Japan Gastroenterological Endoscopic Society). In: HAUBBRICH WS ed - Bockus Gastroenterology. Philadelphia, Saunders, 1995.

51. HENKE F \& LUSBARCH O eds - Handbuch der Speziellen Pathologiscen Anatomie und Histologie. Berlin, Julius Springer, 1929.

52. JASS JR, ATKIN WS, CUZICK J et al. - The grading of rectal cancer. Historical perspectives and a multivariate analysis of 447 cases. Histopathology 1986; 10:437-59.

53. RAWET V - Carcinoma colorretal: estadiamento e parâmetros prognósticos. São Paulo, 1998. (Tese - Mestrado, Faculdade de Medicina da Universidade de São Paulo). 
54. REX DK, JOHNSON DA, LIEBERMAN DA et al. - Colorectal cancer prevention 2000: screening recommendations of the American College of Gastroenterology. Am J Gastroenterol 2000; 95:868-77.

55. WINAWER SJ, FLETCHER RH, MILLER L et al. - Colorectal cancer screening: clinical guidelines and rationale. Gastroenterology 1997, 112: 594-642.

56. STANDARDS COMMITTEE, AMERICAN SOCIETY OF COLON AND RECTAL SURGEONS - Practice Parameters for the Detection of Colorectal Neoplasms, 1.999.

57. MAXFIELD RG - Colonoscopy as a routine preoperative procedure for carcinoma of the colon. Am J Surg 1984; 147: 477-80.

58. GOWEN GF - The impact of colonoscopy on colorectal carcinoma. Am Surg 1991; 57: 254-8.

59. REX DK, MARK D, CLARKE B et al. - Flexible sigmoidoscopy plus air-contrast barium enema versus colonoscopy for evaluation of symptomatic patients without evidence of bleeding. Gastrointest Endosc 1995; 42: 312-8.

60. REX DK - Barium enema in 1995: where are we now? Endoscopy $1995 ; 27: 200-2$

61. RITTENHOUSE MC \& COPELAND EM III - Carcinoma in situ of the distal part of the colon and of the rectum. Surg Gynecol Obstet 1978; 146: 225-9.

62. WOLFF WI \& SINYA H - Definitive treatment of malignant polyps of the colon. Ann Surg 1975; 182: 516-25.

63. SHATNEY CH, LOBER PH \& SOSIN H - Metastasis from a pedunculated adenomatous colonic polyp with focally invasive carcinoma: report of a case. Dis Colon Rectum 1975; 67-71.

64. KIM CY \& FLEISCHER DE - Colonic chromoscopy. A new perspective on polyps and flat adenomas. Gastrointest Endosc Clin North Am 1997; 7 (3): 423-37.

65. IISHI H, TATSUTA M, OKUDA S et al. - Diagnosis of colorectal tumors by the endoscopic Congo-red methylene blue test. Surg Endosc 1994; 8: 1308-11.

66. KUDO S, TAMURA S, NAKAJIMA T et al. - Diagnosis of colorectal tumorous lesions by magnifying endoscopy. Gastrointest Endosc 1996; 44: 8-14.

67. HARA AK, JOHNSON CD, REED JE et al. - Computed tomographic colography (virtual colonoscopy): feasibility of a novel technique. Gastroenterology 1996; 110: 290-4.

68. DUKES CE - The classification of cancer of the rectum. J Pathol Bacteriol 1932; 35: 3223-32.

69. ARAUJO SEA - Valor prognóstico do conteúdo celular de DNA (ploidia) e da atividade proliferativa tumoral no câncer colorretal. Comparação com as variáveis clínico-patológicas convencionais. São Paulo, 1999. (Tese - Mestrado, Faculdade de Medicina da Universidade de São Paulo).

70. FENOGLIO CM, KAYE GI \& LANE N - Distribution of human colonic lymphatics in normal, hyperplastic and adenomatous tissue. Gastroenterology 1973; 64: 51-66.

71. MORSON BC - Factors influencing the prognosis of early cancer of the rectum. Proc R Soc Med 1966; 59: 607-8.
72. MASON AY. Rectal cancer. The spectrum of elective surgery. J R Soc Med 1976; 69: 237-44.

73. DE LANGE EE, FECHNER RE, EDGE SB et al. - Preoperative staging of rectal carcinoma with MR imaging: surgical and histopathologic correlation. Radiology 1990; 176: 623-8.

74. GUINET C, BUY JN, SEZEUR A et al. - Preoperative assessment of the extension of rectal carcinoma: correlation of MR, surgical and histopathologic findings. J Comput Assist Tomogr 1988; 12: 209-14.

75. SOUZA PMSB, HABR-GAMA A, SOUSA JR AHS et al. - Valor da ultrassonografia intra-retal na avaliação da resposta à radio e quimioterapia como primeiro tratamentro do câncer da porção distal do reto. Rev Bras Colo-Proct 1998; 18:17-21.

76. YOSHIDA M, TSUKAMOTO Y, NIWA Y et al. - Endoscopic assessment of invasion of colorectal tumors with a new highfrequency ultrasound probe. Gastrointest Endosc 1995; 587-92.

77. SHIMIZU S, TADA M \& KAWAI K - Use of endoscopic ultrasonography for the diagnosis of colorectal tumors. Endoscopy 1990; 22:31-4.

78. SNADY H - Role of endoscopic ultrasonography in diagnosis, staging and outcome of gastrointestinal diseases. Gastroenterol 1994 2:91-110

79. CHRISTIE JP - Malignant colon polyps. Cure by colonoscopy or colectomy? Am J Gastroenterol 1984; 79:543-7.

80. COLACCHIO TA, FORDE KA \& SCANTLEBURRY VP Endoscopic polypectomy: inadequate treatment for invasive colorectal carcinoma. Ann Surg 1981; 194: 704-7.

81. NIVATVONGS S \& GOLDBERG SM - Management of patients who have polyps containing invasive carcinoma removed via colonoscope. Dis Colon Rectum 1978; 21:8-11.

82. NIVATVONGS S, ROJANASAKUL A, REIMAN HM et al. - The risk of lymph node metastasis in colorectal polyps with invasive adenocarcinoma. Dis Colon Rectum 1991; 34:323-8.

83. CRANLEY JP - Proper management of the patient with a malignant colorectal polyp. Gastrointest Endosc Clin North Am 1993 3:661-72.

84. NIVATVONGS S - Complications in colonoscopic polypectomy. An experience with 1555 polypectomies. Dis Colon Rectum 1986; 29:825-30.

85. MUTO T, SAWADA T \& SUGIHARA K - Treatment of carcinoma in adenomas. World J Surg 1991; 15:35.

86. STEIN BL \& COLLER JA - Tratamento dos pólipos colorretais malignos. Clín Cir Am N 1993; 1: 51-72.

87. POULARD JB, SHATZ B \& KODNER I - Preoperative tatooing of polypectomy site. Endoscopy 1985; 17: 84-5.

88. WILLIAMS CB, WHITEWAY JE \& JASS J - Practical aspects of endoscopic management of malignant polyps. Endoscopy 1987; 19:31-7

89. MATHUS-VIEGLEN EMH \& TYTGAT GNJ - Laser ablation and palliation in colorectal malignancy: results of a multicenter inquiry. Gastrointest Endosc 1986; 32:393-6. 
90. SCHULZE S \& LYNG KM - Palliation of rectosigmoid neoplasms with Nd:YAG laser treatment. Dis Colon Rectum 1994; 37: 882-4.

91. KIEFHABER P, HUBER F \& KIEFHABER K - Palliative and preoperative endoscopic neodymium:YAG laser treatment of colorectal carcinoma. Endoscopy 1987; 19:43-6.

92. ECKHAUSER ML - Laser therapy of colorectal carcinoma. Surg Clin North Am 1992; 72:597-607.

93. HERRERA L - Photodynamic therapy for colorectal neoplasia. Seminars Colon Rectal Surg 1993; 3:57-61.
94. REY JF, ROMANCZYK K \& GREFF M - Metal stents for palliation of rectal carcinoma: a preliminary report on 12 patients. Endoscopy 1995; 27 : 501-4.

95. SAIDA Y, SUMIYAMA Y, NAGAO J et al. - Stent endoprosthesis for obstructing colorectal cancers. Dis Colon Rectum 1996; 39:552-5.

96. RAIJMAN I, SIEMENS M \& MARCON N - Use of an expandable Ultrafle ${ }^{\circledR}$ stent in the treatment of malignant rectal stricture. Endoscopy 1995; 27: 273-6.

97. VIRGO K, VERNAVA A, LONGO W et al. - Cost of patient follow up after potentially curative colorectal cancer treatment. J Am Med Assoc 1995; 273: 1837-41.

Received for publication the $31 / 10 / 00$ 